\title{
Contemporary educational techniques of studying finance and financial markets
}

\author{
Alexander Suyetin ${ }^{1, *}$, Sergei Suyetin ${ }^{1}$ and Mikhail Zharikov ${ }^{1}$ \\ ${ }^{1}$ Moscow Technological Institute, 199334, Moscow, Russia
}

\begin{abstract}
The article is dealing with modern techniques of teaching students as well as interested parties of various courses in economic disciplines. The article covers new approaches to studying finance and financial markets. The article shows the necessity of studying finance and financial markets. The authors come up with the proposals how to improve the educational level of different categories of society. The article considers the methods of distant learning when working on the financial markets.
\end{abstract}

\section{Introduction}

The world economy develops really fast these days. Education should also follow the latest achievements of science and technology.

Financial knowledge is crucially important for every human being irrespective of trade and educational level. This can be explained by the fact that each of us comes to dealing with the financial calculations at home, economic decisions taken by the government in manufacturing, pensioniers' benefits, the consequences of crises, etc.

As to the target audience education in finance can be divided into the following categories:

- schoolchildren;

- college students;

- working population;

- corporate top managemnet, chief stuff, leading specialists.

In the education process of each of these categories there may be singled out a general part, i.e. fundamental knowledge, and a specific part, which is connected with age, level of education and intetersts

\section{Analysis and discussion}

One of the main conditions for the development of As to the schoolchildren, their interest towards finance is only being formed. It it at this stage that the scientific understanding of their nature and laws is really important. At the same time the schoolchildren wait for easy results in accumulating knowledge and their practical application.

The students study finance already from the point of view of professional knowledge. They have a basis for a deeper understanding of scientific accomplishments but often do not have practical experience in the profession they have chosen.
The working population in the field of studying finance can be divided into those who learn finance in a professional dimension and those whose job is hardly connected with finance but who are willing to deeper understand the meaning of this science both for the further use at work and ordinary homegrown comprehension.

Companies' top management and chief stuff are usually interested in finance only from a narrow-looking point of view of its practical application. The representatives of this category have significant professional experience but very little spare time which may be invested into acquiring new knowledge.

In financial education of the leading roles should be given to studying financial markets. Lately they have attracted attention of all the above categories of the population, but a low level of knowledge instead of expected profit very often incurs quite heavy material and moral hazard.

These markets are represented by various financial instruments, however, the most actual, liquid of them is the funds market (stocks and bonds) and the time-frame market (futures and options). The workings of the financial market concern the whole population without exceptions: everything that happens on the stock exchange today is going to influence our life already in the nearest future. For example, bad news of the banking sector is likely to increase the cost of loans and make them less accessible, whereas, a surge in stocks, say, in the trading sector demonstrates active development of these enterprises, and you are able to consider opportunities of investing money into their commercial paper.

According to our observations, a significant part of events that occur on the stock exchange often turns out to be a total surprise for an amateur, as a result of which both ordinary people and unfortunately many professionals begin to panic and make mistakes. That for

* Corresponding author: ansuetin.mti@gmail.com 
example happened in Russian two times already for the last two years: in late 2014 the dollar's exchange rate started increasing dramatically, and many people bought the dollar at its very peak (at 80 roubles per a dollar, fig. 1) [1], after which the exchange rate dropped just as unexpectedly down to 49 roubles. It decreased by more than $30 \%$. The most unfortunate thing about this story is that it repeated a year later - by the end of January 2016 (fig. 2) [1], when one more time there were quite a many purchasers of the dollar at $85-86$ roubles a unit, after which it dropped down to 76 rouble in the course of several days (an eleven percent decrease). As a rule this situation is being exercerbated by the fact that the purchasers had taken advantage of the credit leverage and had not turned to stop-orders. For many people this was an irreversible financial mistake.



Fig. 1. US dollar exchange rate, roubles, time-frame 4 hours, December 2014.

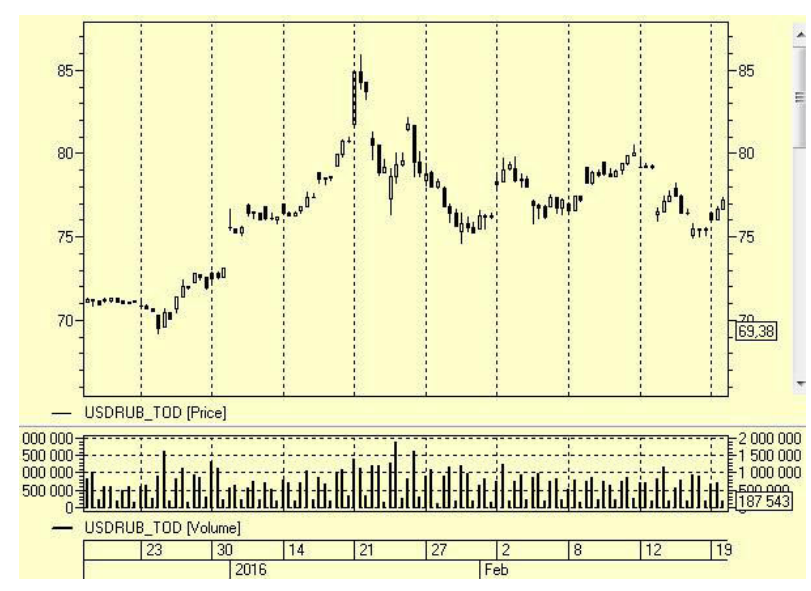

Fig. 2. US dollar exchange rate, roubles, time-frame 4 hours, January 2016.

Thus we can see there is a constant need in introducing financial education to the masses, so that people could use their money more effectively and did not get caught up in the conventional financial traps.

Another problem of poor education is that there are considerable numbers of pseudo-financial companies. At the present moment in Russia there are companies who advertise themselves quite aggressively position themselves as "the participants of the financial market", "financial companies", etc. What is hidden behind them are often financial pyramids that try to look like brokerages by using special terminology connected with the financial market. A professional can immediately see through this. However an ordinary person would find it difficult to see this through, since it is important to know what kind of licenses there should be in order to get the right to work on the financial market, what types of contracts are being concluded there, etc.

Thus we are able to see that today the significance of financial education is extremely high.

At the same time there are certain universities that produce financial professionals using conventional techniques. However, as we can understand the efficiency of the educational process should still be increased even further.

We propose the following fundamental aspects of highly efficient financial education:

1. using e-libraries;

2. listening to business radio stations and watching business channels (such as http://tv.rbc.ru, Rossiya-24, Vesti-FM, CNN, BBC, etc.) [2-6];

3. regular reading of thematic websites such as https://www.fitchratings.com/site/fitch-home, http://www.bloomberg.com, etc.) [7-9];

4. distant learning.

E-libraries allow each person irrespective of their place of residence (whether it is a big city or a small village) to have access to the latest scientific literature. Financial education is very tightly tied to the current situation, which is why the education should be based upon the latest news, market events and works of contemporary scientists.

Regular reading of thematic websites, listening to the business radio stations and watching to the business channels constitute a very significant part of the educational process. The thing is that you should study any science using practical examples. For instance, chemists conduct empirical experiments, mathematicians solve equations, and biologists study flora and fauna.

For a financier that practical experience would be his/her work and observations in the economic business environment.

According to our observations, the students who regularly acquaint with economic news, read analysts' opinions, experts' workouts come to possess a certain idea of economic reality. Very often these opinions can be false. Let it be so, for by pointing out at the mistakes in them we give the students new knowledge and skills to do right conclusions.

At the same time even professionals who do not read business newspapers and are not interested in business news in general altogether, even when they have a big practical experience, standstill or stagnate at a particular moment in their professional development and very soon begin to be lagging behind the newcomers in the quality of what they do.

One of the leading directions in education should be given to distant learning. Distant learning is very often a single opportunity for the people living in faraway areas to get education. In order to learn distantly it is enough for you to have at home a computer and the access to the 
Internet. Besides, this type of education is optimal for busy people who do not regularly have spare time to improve their level of education. This is the reason for their not being able to attend traditional courses of study. Distant learning is also ideal for disabled people for whom it is difficult to get to universities or libraries.

Distant learning can be used both by the way of getting full-fledged, comprehensive higher education and through various educational courses.

Distant learning in the field of finance is most significant when studying financial markets and trading programs (trading terminals).

Distant learning should include:

1. educational materials which can be uploaded from websites such as text-books, presentations, etc.;

2. webinars where teachers explain a lecture and answer the questions of the audience;

3. individual learning such as homework;

4. a direct connection of a teacher to the computer of a user so that it were possible to figuratively showcase such and such activities in a computer program as well as check whether a student's home-task is correct and do the aftermath.

Distant learning is already a quite popular type of education in the whole world. In this article we are going to focus more on one of the above points we have made before, i.e. a direct connection of a teacher to the computer of a user.

Distant connection to the computer of a user is absolutely necessary when studying and analyzing financial markets, and, most importantly, when supervising the activities of amateurs on the trading floor.

For a distant connection it is quite possible to use the program Team Viewer [10] (fig. 3) or any other analogous product, whereas for oral communication you should make use of Skype [11] or similar programs as well.

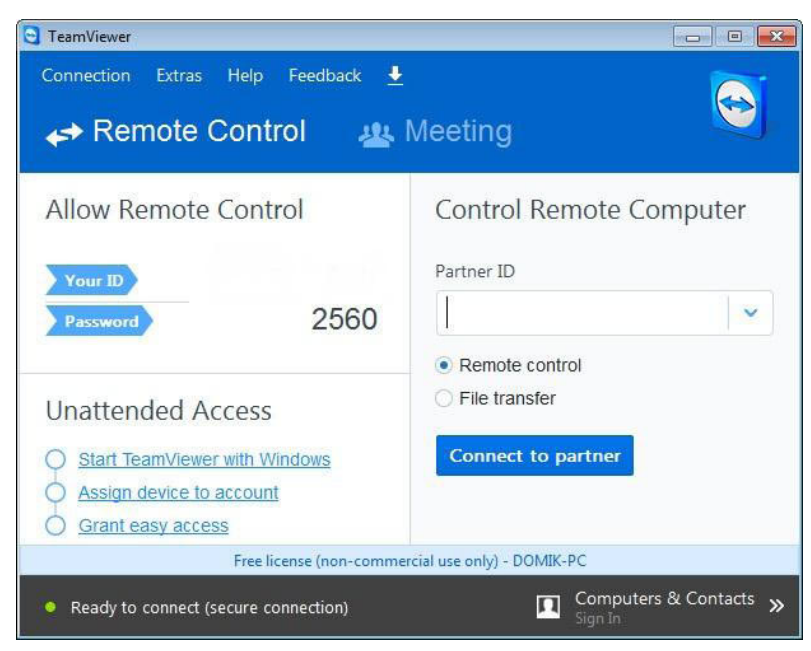

Fig. 3. The interface of the program Team Viewer

We propose the following scheme of a complex usage of these programs:

1. the programs should be installed in the computer of a teacher and that of a user;
2. when there is a need for connection, the user starts Team Viewer and gets a password which he/she sends over to the teacher via Skype, for example. The teacher enters the password in the working Team Viewer and gets connection to the user. The whole operation of getting connection is analogous to Blue Tooth or Wi-Fi;

3 . using the Team Viewer the teacher acts on the user's computer, whereas via Skype or any other similar program they communicate, make explanations, stipulate the most difficult aspects of learning.

Now we introduce an example of the method we worked out of the complex usage of distant learning programs to study how to work on the financial markets.

Our experience shows that the most difficulty when learning how to trade student find in practical application of trading terminals. In Russia one of the most popular terminals is the program Quik. By the way, the above operations will be similar for other analogous programs as well such as MetaTrader [12].

Having studied the theory, students are introduced to a trading terminal, they analyze the current market situation, make transaction, analyze and control their outcomes. Together with the students we study different trading strategies, approaches of technical analysis, etc. One of the most well-known trading strategies in the world is the method of Bill M. Williams that he describes in his books Trading Chaos [14] and New Trading Dimensions [15]. When learning his methods you require a constant control over a market situation and, most importantly, a correct understanding of the market.

He proposes the indicator called Alligator of Bill Williams which is shown in fig. 4. Besides, he uses not the Japanese candles but bars.

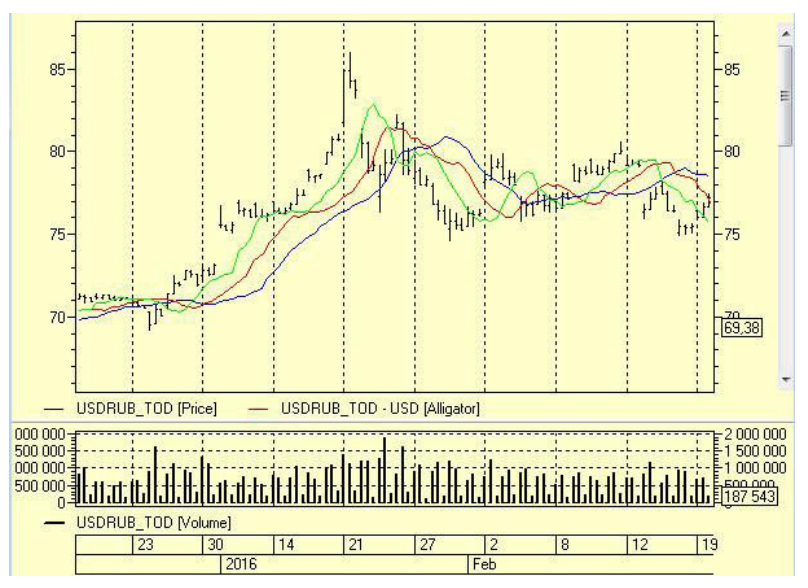

Fig. 4. Alligator of Bill Williams on the chart of dollar-torouble exchange rate. Time frame $4 \mathrm{hrs}$

Via distant connection the students always have an opportunity to ask their teacher whether they correctly understand the current market situation and, having received an answer, they are able to correct the mistakes and continue work.

Also in every university the issues of the technical analysis are touched upon, when studying the financial markets. Without a distant connection, and communicating only via the phone or e-mail, it is 
practically impossible to show the students the correct methods of analysis and correct their mistakes.

Our practical experience shows that the most difficulty the students find in learning the Fibonacci Fan (fig. 5).

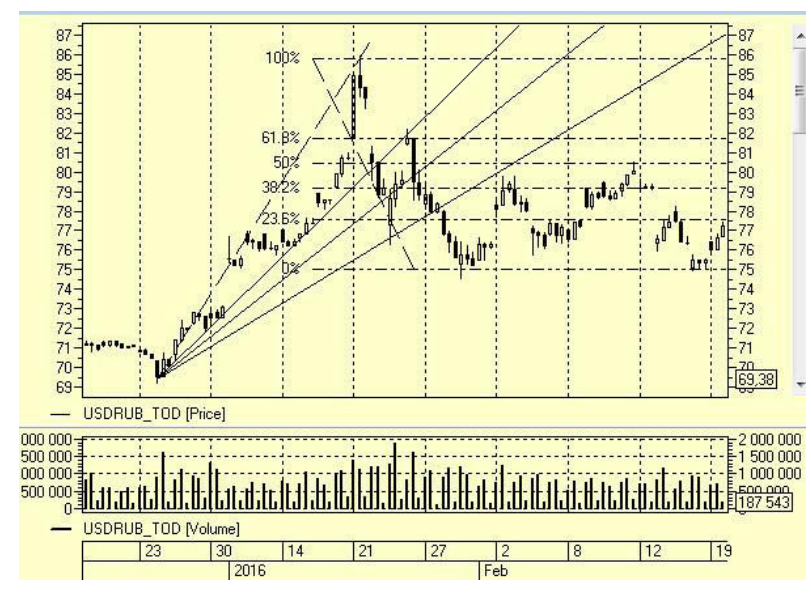

Fig. 5. The Fan and Lines of Fibonacci on the of dollar-torouble exchange rate. Time frame $4 \mathrm{hrs}$

Different figures of the technical analysis such as head and shoulders, flag, etc. are quite well understood by the students. They even do it quite well when they read presentations and newspapers. The figures of Fibonacci despite their being externally simple require a certain amount of intuition when choosing a starting point to construct the Fibonacci Fan (for a trend) or the Line of Fibonacci (for a by-side movement of the market).

The authors of the article have experience in helping amateur trading students in emergencies. For example, there was a case when one of the students being a client of a brokerage when working with the trading terminal had accidentally closed all the windows showing the graphs, and for that reason he could not make transactions. What he did was he contacted us, and consequently we established a distant connection to his computer, restored the trading terminal and checked his understanding of the technical analysis of the current market situation. And though the student was on the demo account where there was no flow of real money, the whole situation was quickly reversed for the better. The student himself got a real practical experience that way. At this point it is important to note a very crucial moment: the student had opened the position late in the evening at 10 (the trading session in section FORTS at the Moscow Exchange lasts until 23:50), so to correct the mistakes he had made was practically impossible without a distant connection. However, if we were to consider the same situation in the afternoon or working hours, then the time for corrections would have been missed irreversibly.

\section{Conclusions}

Various approaches and personal skills are required for effective learning in modern society: for example, ability to make relations and see the sense between spheres of knowledge, concepts and ideas is one of the major skills ensuring effective activity in the modern world. Timely renewal of knowledge is a necessary feature of modern education. Moreover, this is a process of decisionmaking (ability to choose, analyze, organize, classify, evaluate incoming information), which presupposes high level of development of informative and cognitive independence of students' personality.

\section{References}

1. http://bcs-express.ru/kotirovki-igrafiki/usd000000tod/liquidity;

2. http://tv.rbc.ru;

3. http://www.vesti.ru/onair/;

4. http://radiovesti.ru/;

5. http://edition.cnn.com/;

6. http://www.bbc.com/;

7. http://www.rbc.ru;

8. https://www.fitchratings.com/site/fitch-home;

9. http://www.bloomberg.com;

10. https://www.teamviewer.com/ru/;

11. http://www.skype.com/ru/;

12. http://www.metatrader4.com/;

13. http://www.profitunity.com/;

14. B.M. Williams. Trading Chaos: Maximize Profits with Proven Technical Techniques (A Marketplace Book, 1995);

15. B.M. Williams. New Trading Dimensions: How to Profit from Chaos in Stocks, Bonds, and Commodities (1998) 